\title{
PARASITISASI DAN KAPASITAS REPRODUKSI COTESIA FLAVIPES CAMERON (HYMENOPTERA: BRACONIDAE) PADA INANG DAN INSTAR YANG BERBEDA DI LABORATORIUM
}

\author{
Purnomo ${ }^{1}$
}

\begin{abstract}
Parasitization and reproductive capacity of Cotesia flavipes Cameron (Hymenoptaera: Braconidae) on different hosts and instar in laboratory. C. flavipes is an important parasitoid on sugar cane spotted borer, Chilo sacchariphagus Bojer. The biology informations of $C$. flavipes is needed in order to make more effective as acontroling agent. The objectives of this research were to investigate the effect of host species (C. sacchariphagus, C. auricilius, Scirpophaga nivella) and different instar on parasitization and reproductive capacity of $C$. flavipes. The results showed that the best host for C. flavipes is C. sacchariphagus and at fifth instar of C. sacchariphagus.
\end{abstract}

Key words: Cotesia flavipes, parasitization, reproductive capacity

\section{PENDAHULUAN}

Kebutuhan gula di Indonesia selalu meningkat dari tahun ke tahun dan hingga saat ini belum mampu dipenuhi oleh produksi dalam negeri (Hafsah, 2002; Kompas, 2003). Oleh karena itu diperlukan upaya peningkatan produksi gula nasional secara optimal. Budidaya tanaman tebu yang merupakan faktor kunci penentu produksi gula harus terus menerus diperbaiki. Salah satu kendala dalam budidaya tebu adalah adanya serangan berbagai jenis hama yang terjadi sepanjang pertumbuhan tanaman (Ganeshan, 2001; Sunaryo, 2003).

Penggerek batang tebu bergaris, Chilo sacchariphagus Bojer (Lepidoptera: Pyralidae) adalah salah satu hama yang sangat berbahaya pada tanaman tebu. Serangga hama ini menyerang tanaman tebu sejak dari awal tanam hingga saat panen. Serangan dimulai oleh larva muda yang sangat aktif menggerek daun muda, kemudian turun menuju ruasruas batang di bawahnya sampai mencapai titik tumbuh dengan luka gerekan yang demikian dalam hingga dapat mengakibatkan kematian tanaman tebu (Ganseshan, 2001; Kalshoven 1981). Selanjutnya Sunaryo (2003) menyatakan bahwa populasi larva C. sacchariphagus mulai meningkat dari umur tanaman 3,5 bulan dan mencapai puncaknya pada saat tanaman berumur 9,5 bulan. Tingkat serangan hama penggerek batang pada pertanaman tebu di Lampung cenderung meningkat dari 5\% pada tahun 1998 menjadi $12 \%$ pada tahun 2002 .

Salah satu musuh alami yang dapat digunakan untuk mengendalikan penggerek batang tebu adalah parasitoid Cotesia flavipes Cameron (Hymenoptera: Braconidae) (Ganeshan \& Rajableetatus, 1997). Menurut Sunaryo (2003) upaya pemanfaatan C. flavipes belum memberikan hasil yang efektif dalam mengendalikan hama penggerek batang tebu. Oleh karena itu berbagai penelitian yang bertujuan untuk mencari faktor-faktor yang dapat meningkatkan keefektifan penggunaan $C$. flavipes perlu terus dilakukan.

Penelitian ini bertujuan utuk mengetahui tingkat parasitisasi dan kapasitas reproduksi (reproductive capacity) C. flavipes pada berbagai jenis (spesies) inang dan berbagai ukuran (instar) larva inang.

\section{METODE PENELITIAN}

Penelitian dilaksanakan di Laboratorium Biocontrol, Research and Development PT Gunung Madu Plantations (PT GMP), Gunung Batin Lampung Tengah. Penelitian berlangsung dari bulan Agustus 2005 hingga Maret 2006.

Parasitoid $C$. flavipes yang digunakan pada percobaan diperoleh dari hasil pengumpulan sejumlah kokon yang berasal dari pertanaman tebu milik PT GMP. Dari sejumlah kokon parasitoid yang terkumpul, satu kelompok kokon dimasukkan ke dalam tabung gelas (tinggi $20 \mathrm{~cm}$; diameter $3 \mathrm{~cm}$ ) yang disumbat dengan kapas. Sejumlah imago parasitoid yang muncul dari kokon tersebut diberi pakan berupa madu dengan konsentrasi $10 \%$ yang ditempelkan pada dinding tabung. Tabung-tabung gelas berisi parasitoid ditutup dengan kain hitam untuk mengurangi keaktifan gerak imago parasitoid.

\footnotetext{
${ }^{1}$ Dosen Jurusan Proteksi Tanaman, Fakultas Pertanian, Universitas Lampung

J1. Prof. Sumantri Brojonegoro No. 1 Bandar Lampung 35145
} 
Uji Pengaruh Jenis Inang. Serangga uji yang digunakan adalah penggerek batang tebu bergaris (Chilo sacchariphagus), penggerek batang tebu berkilat (Chilo auricilius), dan penggerek pucuk (Scirpophaga nivella). Uji pengaruh jenis inang dilakukan di laboratorium mengunakan larva penggerek batang tebu sehat yang telah dipelihara sebelumnya di laboratorium dan larva penggerek pucuk yang diperoleh dari lapangan. Larva penggerek batang dimasukkan ke dalam tabung plastik (tinggi $7 \mathrm{~cm}$; diameter $14 \mathrm{~cm}$ ) yang berisi pucuk tebu yang telah dilubangi. Ke dalam setiap wadah dimasukkan 20 ekor larva instar 3 dari masing-masing jenis serangga uji. Pemarasitan dilakukan dengan memasukkan 1 induk parasitoid betina yang sudah kawin ke dalam masing-masing wadah kemudian menutupnya. Diagram alir pelaksanaan uji pengaruh jenis inang selengkapnya dapat dilihat pada Gambar 1.

Percobaan disusun dalam Rancangan Acak Lengkap (RAL) dengan empat ulangan. Pengamatan dilakukan pada hari ke-3, 7, dan 12 setelah pemarasitan dengan cara memeriksa setiap larva inang dan menghitung jumlah larva inang yang terparasit serta menghitung jumlah parasitoid yang muncul pada hari ke-15 sampai hari ke-20 setelah pemarasitan. Peubah yang diamati adalah persentase parasitisme (Ps) dan kapasitas reproduksi parasitoid (Ro). Kedua peubah tersebut dihitung dengan menggunakan rumus:

\section{Persentase parasitisme (Ps)}

$$
\mathrm{Ps}=\mathrm{P} / \mathrm{S} \times 100 \%
$$

Ps $=$ persentase parasitisme

$P=$ jumlah larva inang yang terparasit

$\mathrm{S}=$ total larva inang

2. Kapasitas reproduksi parasitoid (Ro)

$$
\text { Ro }=\text { Jumlah kokon dan imago parasitoid yang }
$$
muncul.

Uji pengaruh ukuran (instar) larva inang. Uji pengaruh instar dilakukan di laboratorium dengan menggunakan larva $C$. sacchariphagus hasil pemeliharaan. Dengan memperhatikan kepraktisan di lapangan, fase instar larva ditentukan berdasarkan ukuran larva inang: larva muda/kecil (instar 1-2), panjang kurang dari 1,5 cm; larva sedang (instar3-4), panjang sama dengan $1,5 \mathrm{~cm}$; larva besar/tua (instar 5), panjang lebih dari 1,5 $\mathrm{cm}$. Percobaan disusun dalam Rancangan Acak Lengkap (RAL) dengan empat ulangan.

Dua puluh ekor larva dari tiap fase (sesuai perlakuan) dimasukkan ke dalam tabung plastik (tinggi $8 \mathrm{~cm}$; diameter $6 \mathrm{~cm}$ ) yang telah berisi bagasse dan gulungan pelepah tebu segar. Setelah itu sepasang imago parasitoid dimasukkan ke dalam tabung plastik itu. Dua sampai tiga tetes madu (konsentrasi 10\%) sebagai sumber pakan parasitoid diteteskan pada tutup tabung yang bagian tengahnya telah dilapisi kain kasa sebagai sumber sirkulasi udara bagi larva dan parasitoid.

Cara pengamatan dan peubah yang dihitung pada uji pengaruh instar sama dengan cara pengamatan dan peubah yang dihitung pada uji pengaruh jenis inang.

\section{HASIL DAN PEMBAHASAN}

\section{Pengaruh Jenis Inang}

Hasil pengamatan menunjukkan bahwa parasitoid C. flavipes dapat memarasit larva C. saccariphagus dan C. auricilius tetapi tidak dapat memarasit S. nivella (Tabel 1). C. flavipes merupakan salah satu musuh alami penting yang berpotensi untuk mengendalikan hama penggerek $C$. sacchariphagus (Sunaryo, 1984). Parasitoid ini di ketahui juga dapat memarasit penggerek batang tebu berkilat C. auricilus (Kalshoven, 1981). Hal ini terbukti pula pada penelitian ini, yang menunjukkan bahwa C. flavipes dapat memarasit 10 ekor larva dari 80 ekor larva $C$. sacchariphagus yang disediakan. Pada inang C. auricilius, parasitoid C. flavipes dapat memarasit 3 larva dari 80 larva yang disediakan.

Parasitisasi C. flavipes yang lebih tinggi pada C. sacchariphagus jika dibandingkan dengan inang C. auricilius kemungkinan berkaitan dengan kairomon yang diproduksi oleh $C$. sacchariphagus yang tidak terdapat pada jenis inang lain. Hasil penelitian Harsanto \& Sunaryo (1983) menunjukkan bahwa C. flavipes akan tertarik pada C. auricilius jika inang tersebut telah dilumuri frass (sisa gerekan) C. sacchariphagus.

Tidak dihasilkannya kokon parasitoid pada inang $S$. nivella mungkin terjadi karena inang ini tidak disukai oleh parasitoid. Ketidaksukaan ini dapat 


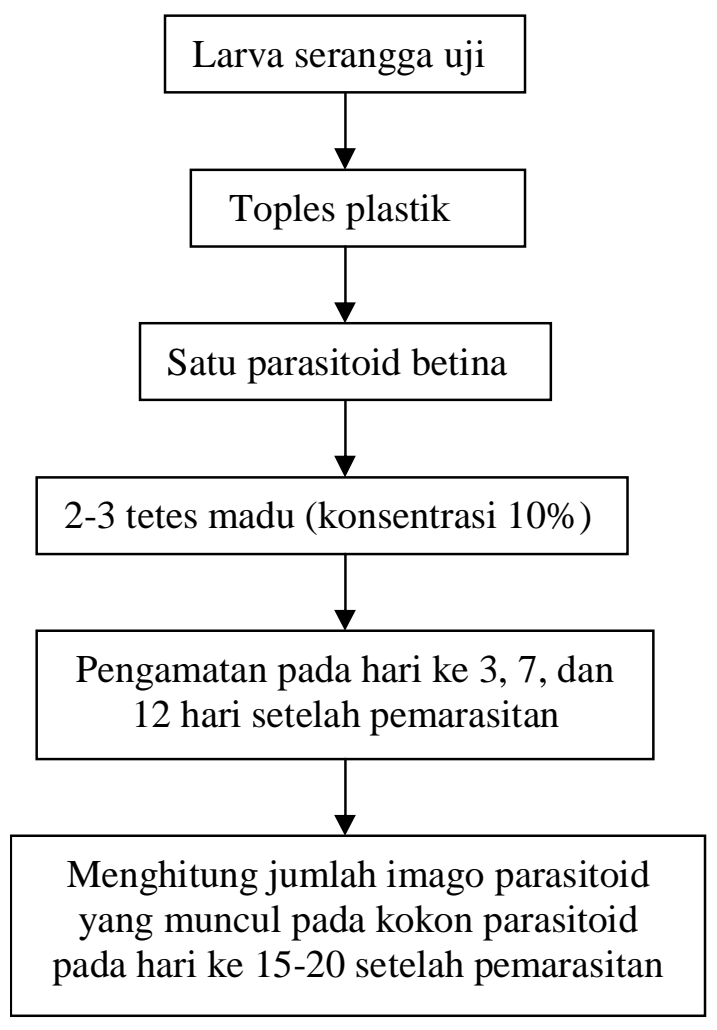

Gambar 1. Diagram alir pelaksanaan uji pengaruh jenis inang.

Tabel 1. Tingkat parasitisasi Cotesia flavipes pada tiga jenis inang

\begin{tabular}{lc}
\hline Jenis inang & Inang terparasit $(\%)$ \\
\hline C. sacchariphagus & $12,50 \mathrm{a}$ \\
C. auricilius & $3,75 \mathrm{~b}$ \\
S. nivella & $0,00 \mathrm{~b}$
\end{tabular}

BNT $0,05=5,16$

Keterangan: angka yang diikuti huruf yang sama tidak berbeda nyata menurut uji BNT pada taraf nyata 5\%.

dipengaruhi oleh jenis pakan yang dikonsumsi oleh $S$. nivella yang berbeda dengan yang dikonsumsi C. sacchariphagus dan C. auricilius. Askew \& Shaw (1989) berpendapat bahwa tumbuhan inang dapat juga mempengaruhi komposisi nutrisi serangga herbivora yang hidup padanya, dan keadaan ini dapat berpengaruh terhadap parasitoidnya.

Meskipun belum sepenuhnya menggambarkan kapasitas reproduksi yang sesungguhnya, pengamatan jumlah kokon yang terbentuk berikut imago parasitoid yang berhasil muncul dapat digunakan sebagai indikator kesesuaian inang. Rata-rata jumlah kokon C. flavipes yang terbentuk pada inang C. sacchariphagus adalah 58,50 dan angka ini lebih tinggi dibandingkan dengan yang terbentuk pada inang $C$. auricilius yang rata-rata berjumlah 30,75 (Tabel 2.). Selain itu, jumlah imago $C$. flavipes lebih banyak muncul dari kokon yang ditemukan pada C. sacchariphagus.

Perbandingan jantan dan betina (sex ratio) imago $C$. flavipes pada hasil penelitian ini adalah 1:2 untuk yang hidup pada inang $C$. sacchariphagus dan 
Tabel 2. Jumlah kokon dan imago Cotesia flavipes pada tiga jenis inang

\begin{tabular}{lccc}
\hline Jenis inang & $\begin{array}{c}\text { Jumlah kokon } \\
\text { (ekor) }\end{array}$ & $\begin{array}{c}\text { Imago jantan } \\
\text { (ekor) }\end{array}$ & $\begin{array}{c}\text { Imago betina } \\
\text { (ekor) }\end{array}$ \\
\hline C. sacchariphagus & $58,50 \mathrm{a}$ & $13,75 \mathrm{a}$ & $25,50 \mathrm{a}$ \\
C. auricilius & $30,75 \mathrm{ab}$ & $4,75 \mathrm{a}$ & $21,50 \mathrm{a}$ \\
S. nivella & $0,00 \mathrm{~b}$ & $0,00 \mathrm{~b}$ & $0,00 \mathrm{a}$ \\
\hline \multicolumn{1}{c}{ BNT 0,05 } & 43,14 & 10,02 & 33,28
\end{tabular}

Keterangan: angka yang diikuti huruf yang sama (arah vertikal) tidak berbeda nyata menurut uji BNT pada taraf nyata $5 \%$.

1:4 untuk yang hidup pada inang $C$. auricilius. Keadaan ini menunjukkan bahwa $C$. flavipes memiliki kemampuan yang cukup baik untuk bertahan hidup dan menghasilkan keturunan selama masih ditemukan dua jenis inang itu

\section{Pengaruh Ukuran (Instar) Larva}

Hasil penelitian menunjukkan bahwa larva C. sacchariphagus yang terparasit $C$. flavipes hanya larva dengan ukuran terbesar (instar 5, panjang > 1,5 $\mathrm{cm})$. Larva dengan ukuran kecil maupun sedang tidak berhasil diparasit oleh $C$. flavipes (Tabel 3.).

Dalam pemilihan inang, seekor imago parasitoid sangat mempertimbangkan kemungkinan kelangsungan hidup keturunannya. Oleh karena itu, di samping faktor nutrisi, ketersediaan ruang yang sesuai juga merupakan hal yang penting. Bagi C. flavipes, hanya larva berukuran lebih dari $1,5 \mathrm{~cm}$ yang dianggap sesuai bagi keberhasilan hidup keturunannya.

Tingkat parasitisme erat kaitannya dengan kapasitas reproduksi parasitoid. Menurut Doutt et al. (1976) persentase parasitoid sangat menentukan produksi kokon parasitoid dari larva yang terparasit, keberhasilan menjadi imago dan nisbah kelamin zuriat yang dihasilkan, sehingga sangat mempengaruhi kemampuan reproduksi parasitoid.

Ukuran larva inang merupakan faktor utama yang berpengaruh terhadap jumlah kokon parasitoid karena parasitoid $C$. flavipes merupakan parasit gregarius, artinya lebih dari satu individu dapat hidup bersama-sama dalam satu inang (Doutt et al., 1976). Persentase keberhasilan kokon menjadi imago lebih tinggi pada inang berukuran besar. Ini menunjukkan bahwa daya dukung larva besar atau tua lebih baik dibandingkan larva muda.

\section{SIMPULAN}

Dari penelitian ini dapat disimpulkan bahwa tingkat parasitisasi $C$. flavipes dipengaruhi oleh jenis inang. Tingkat parasitisasi $C$. flavipes tertinggi ditemukan pada inang C. sacchariphagus. Kapasitas reproduksi parasitoid $C$. flavipes tertinggi juga terdapat pada inang $C$. sacchariphagus, diikuti pada C. auricilius.

Ukuran (instar) larva inang C. sacchariphagus berpengaruh terhadap tingkat parasitisme dan kemampuan reproduksi $C$. flavipes. $C$. flavipes dapat berkembang dengan baik hanya pada larva instar tua (instar 5), yang panjangnya lebih dari $1,5 \mathrm{~cm}$.

\section{SANWANCANA}

Penulis mengucapkan terima kasih kepada Bapak Ir. Sunaryo (Staf R \& D PT Gunung Madu Plantations) atas bantuan teknis dan fasilitas. Ucapan terima kasih juga ditujukan kepada Ibu Dr. Rosma Hasibuan, Bapak Nur Yasin, M.Si. (Dosen Jurusan Proteksi Tanaman FP Unila), saudari Septina Shalomita dan Devi Agustina (alumni FP Unila) yang berperan bagi terselesaikannya penelitian ini.

\section{DAFTAR PUSTAKA}

Askew, R.R. \& M.R. Shaw. 1989. Parasitoid Comunities: their Size, Structure and Development. Pages: 225-264 in: J. Waage \& D. Greathead, eds. Insect Parasitoids. Academic Press. London.

Doutt, R.L., D.P. Annecke, \& E. Themblay. 1976. Biology and host relationships of parasitoids. Pages: 143-168 in: C.B. Huffaker \& P.S. Messenger, eds. Theory and Practice of 
Tabel 3. Tingkat parasitisme, jumlah kokon, dan persentase kokon menjadi imago C. flapives pada berbagai ukuran larva

\begin{tabular}{lccc}
\hline \multicolumn{1}{c}{ Ukuran (instar) } & $\begin{array}{c}\text { Tingkat } \\
\text { Parasitisme } \\
(\%)\end{array}$ & $\begin{array}{c}\text { Jumlah kokon } \\
\text { (ekor) }\end{array}$ & $\begin{array}{c}\text { Persentase kokon jadi } \\
\text { imago } \\
(\%)\end{array}$ \\
\hline Larva muda (instar 1-2); $<1,5 \mathrm{~cm}$ & 0 & 0 & 0 \\
Larva sedang (instar 3-4); $1,5 \mathrm{~cm}$ & 0 & 0 & 0 \\
Larva tua (instar 5); > $1,5 \mathrm{~cm}$ & 3,75 & 19,75 & 44,35 \\
\hline
\end{tabular}

Biological Control. Academic Press. New York.

Ganeshan, S. 2001. A Guide to the Insect Pests of Sugar Cane in Mauritius. Entomology Department. Mauritius Sugar Industry Research Institute (MSIRI).

Ganeshan, S. \& A. Rajabaleetatus. 1997. Status of parasitoids of the sugar cane spotted borer, Chilo sacchariphagus Bojer (Lepidoptera: Pyralidae) in Mauritius. Mauritius Sugar Industry Research Institute, Reduit, Mauritius. <http://www.Sasta.co.za/1997Congress/agrica bs97. htm. Diakses 15 Mei 2005>.

Hafsah, M.J. 2002. Bisnis Gula di Indonesia. Pustaka Sinar Harapan. Jakarta.

Harsanto, U. \& Sunaryo. 1983. Pembiakan masal Apanteles flavipes Cam., parasit larva penggerek batang tebu. Majalah Perusahaan Gula Indonesia IX (4).
Kalshoven, L.G.E. 1981. The Pests of Crops in Indonesia. Revised and Translated By P.A. van der Laan. Ichtiar Baru - Van Hoeve. Jakarta.

Kompas. 2003. Impor Ilegal Gula dan Beras Mencapai Satu Juta Ton. Harian Kompas, 12 Mei 2003.

Sunaryo. 1984. Kemungkinan penggunaan Apanteles flavipes Cam. Dalam pengendalian Chilo sacchariphagus Boj. Di Gunung Madu. Prosiding Pertemuan Tengah Tahunan II Lahan Kering di Luar jawa. BP3G Pasuruan.

Sunaryo. 2003. Status hama-hama tanaman tebu di GMP. Publikasi internal R \& D PT Gunung Madu Plantations. Lampung Tengah. 